\title{
Avaliação do teor de óleo essencial de Baccharis trimera (Less.) DC. em diferentes embalagens durante $o$ armazenamento
}

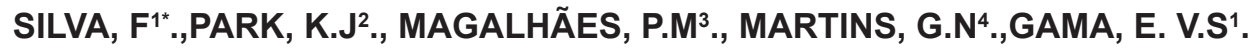
${ }^{1}$ Centro de Ciências Agrárias, Ambientais e Biológicas/CCAAB, Universidade Federal do Recôncavo da Bahia, Rua Rui Barbosa, 710, CEP: 44380-000, Cruz das Almas, Bahia, Brasil. 'Departamento de Engenharia Agrícola/ FEAGRI, Universidade Estadual de Campinas/UNICAMP, ${ }^{3}$ Departamento de Agrotecnologia, CPQBA, UNICAMP, SP, Brasil. ${ }^{4} E P A G R I$, CEP:88350-300, Itajaí, SC, Brasil. *franceli@ufrb.edu.br

\begin{abstract}
RESUMO: O uso de plantas medicinais como fonte terapêutica é milenar e nos últimos anos o seu valor tem aumentado, tanto para a população quanto para a ciência. Várias empresas nacionais e internacionais empregam matéria-prima vegetal na elaboração de seus produtos, o que torna indispensável o cultivo comercial e o beneficiamento pós-colheita destas espécies. $O$ objetivo deste trabalho foi avaliar o teor de óleo essencial de carqueja [Baccharis trimera (Less.) DC.], em três embalagens diferentes ao longo de um ano de armazenamento. Observou-se que ao longo do armazenamento, a embalagem de papel Kraft foi a que melhor preservou a integridade de certas características físicas e químicas do produto, assim como, manteve o teor de óleo ao longo de um ano de armazenamento.
\end{abstract}

\section{Palavras-chave: Baccharis trimera/Armazenamento/Óleo essencial}

ABSTRACT: Assessment of Baccharis trimera (Less.) DC. essential oil content in different packages during storage. The use of medicinal plants as therapeutic source is ancient and has increased in value in recent years for both the population and the science. Several national and international companies use raw plant material in the preparation of their products, making essential the commercial cultivation and the post-harvest processing of these species. The aim of this study was to evaluate the essential oil content of [Baccharis trimera (Less.) DC.] in three different packages over one year of storage. During storage, Kraft-paper package best preserved the integrity of some physical and chemical characteristics of the product and maintained the oil content for one year of storage.

Key words: medicinal plant, essential oil, package, storage

\section{INTRODUÇÃO}

Os óleos essenciais são misturas complexas de compostos voláteis, na maioria, mono e sesquiterpenos. Geralmente odoríferos e líquidos em temperatura ambiente, os Óleos Essenciais são responsáveis pela interação entre os vegetais e o meio no qual habitam desempenhando funções como atração de polinizadores, proteção da planta contra altas temperaturas, dentre outras (Saito e Scramin, 2000; Prins et al., 2006; Jakiemiu, 2008). Os óleos essenciais são utilizados em diversos setores industriais, como por exemplo, na fabricação de fármacos, perfumes, cosméticos, produtos de higiene e limpeza, alimentos e bebidas. Esses óleos podem ser extraídos de caules, flores, frutos e raízes de diversas espécies de vegetais aromáticas e possuem diferentes aplicações. Na indústria alimentícia podem atuar como antioxidantes e antibacterianos, além de reproduzir o sabor e odor da planta utilizada. Cerca de 300 diferentes tipos de óleos essenciais são comercializados, apesar de serem conhecidos aproximadamente 3.000 tipos de óleos essenciais (Busatta, 2006).

O óleo essencial da carqueja é composto principalmente por carquejol, acetato de carquejila e sesquiterpenos (Siqueira et al., 1985; Santos et al., 1988; Sousa et al.,1991). Também apresenta flavonóides como a quercetina, luteolina, nepetina, apigenina, rutina, hispidulina (Soicke e LengPeschlow, 1987; Di Stasi et al. 1988), eupatorina, cirsimaritina, cirsiliol, apigeina, genkwanina e eriodictiol (Kuroyanagi et al., 1985; De Mello e Petrovic, 2000), diterpenos, compostos tânicos e saponinas (Castro et al., 1999; Jarvis et al., 1991; Zdero et al., 1991). 
Na medicina popular a planta é usada como diurética, tônica, digestiva (Carneiro e Fernandes, 1996; Lorenzi e Matos, 2008; Schmidt et al., 2008), protetora e estimulante do fígado, antianêmica, antireumática, depurativa, para o controle da obesidade, diabetes, hepatite e gastroenterites (Castro e Ferreira, 2000). Na agricultura é aproveitada pelas propriedades alelopáticas retardando a velocidade na germinação de sementes (Castro e Ferreira, 2000), inibindo o crescimento micelial de fungos (Ito et al., 2005) e de raízes de trigo (Gonzáles et al., 1993); também é utilizada na indústria de cervejaria como substituto do lúpulo e na aromatização de refrigerantes e de licores (Castro e Ferreira, 2000).

A carqueja é destinada ao comércio nacional e internacional na forma de planta seca (Silva et al., 2001), sendo encontrada também em cápsulas, comprimidos, tinturas ou saches entre outras (Palácio et al., 2007).

A qualidade da droga vegetal depende diretamente de fatores de natureza química, física e biológica, que atuam sobre o produto durante o período de tempo entre a produção e o consumo, que é denominado "vida de prateleira". Neste contexto, a embalagem é de importância fundamental. $\mathrm{O}$ armazenamento de produtos sem a proteção externa da embalagem conduz à oxidação e à degradação de alguns constituintes, o que no caso das plantas medicinais é indesejável, pois o recomendável é justamente preservar a composição física e química. Dentre inúmeras funções, a de maior destaque em embalagem é o fato de entregar ao consumidor o produto com o mesmo nível de qualidade, ou bem próximo a este, dos produtos frescos. Aembalagem atua como barreira de proteção do produto contra o contato direto com o ambiente evitando ou diminuindo assim as contaminações, o manuseio inadequado, e a perda das características do produto. No entanto, a embalagem pode, ela mesma, representar fonte de riscos através da migração ao produto de substâncias da própria constituição. (Mc Guiness, 1996).

As embalagens mais usuais para plantas medicinais secas são: plástico, papel, vidro, e sacos de juta. Dentre estas, destaca-se o polietileno de baixa densidade, o vidro e o papel.

O polietileno de baixa densidade é obtido a partir do gás etileno e, uma vez polimerizado, possui estrutura tridimensional onde os átomos de carbono estão dispostos em zig-zag. A estrutura molecular é complexa e as ramificações presentes são responsáveis por variações nas propriedades, tais como: densidade, dureza, flexibilidade, viscosidade e transparência (Midio e Martins, 2000).

O plástico é o material mais utilizado em embalagens, pois possui resistência, transparência, e tem permeabilidade relativamente baixa ao vapor de água. É quimicamente inerte e praticamente não possui odor e nem transmite sabor significativo aos alimentos (Cabral e Soler, 1978). No entanto, no caso de plantas medicinais aromáticas, acondicionadas por longos períodos, pode ocorrer perda gradual do aroma, uma vez que é permeável a muitos óleos essenciais.

O objetivo deste trabalho foi avaliar o teor de óleo essencial da carqueja durante o período de armazenamento (um ano) em diferentes embalagens (papel kraft, vidro e polietileno).

\section{MATERIAL E MÉTODO}

As plantas utilizadas no experimento foram cultivadas no campo experimental do Centro Pluridisciplinar de Pesquisas Químicas, Biológicas e Agrícolas - CPQBA, da Universidade Estadual de Campinas (Unicamp), localizado em Paulínia - SP, latitude sul $22^{\circ} 48 \mathrm{~min}, 47^{\circ} 0$ min longitude oeste, 669 altitude, solo latossolo vermelho escuro argiloso, e, após seis meses de cultivo, foram colhidas semanalmente.

\section{Processo de Secagem e Embalagens}

Após a secagem à temperatura de $30^{\circ} \mathrm{C}$, em secador a gás e em estufa com circulação forçada de ar até a umidade de $10 \%$, as plantas foram homogeneizadas para permitir amostragem composta, uma vez que a colheita foi semanal. Em seguida as plantas foram acondicionadas nas embalagens de papel Kraft tipo exportação, vidro, e polietileno de baixa densidade, e armazenadas em Ervanário (sala escura, vedada, e com desumidificador) onde foram avaliadas durante o período de um ano. Cada amostra foi de aproximadamente $100 \mathrm{~g}$.

\section{Extração de óleo essencial}

A extração do óleo essencial foi realizada pelo método de arraste por vapor d'água (Martins, 1996; Lopes, 1997; Castro, 1998; Kamada, 1998) (Figura 12). Antes de realizar as extrações do óleo essencial procederam-se testes preliminares com a finalidade de ajustar a metodologia, definindo as seguintes condições: tempo de arraste a vapor de aproximadamente 120 min, massa de plantas frescas e secas para a extração entre 100 a $145 \mathrm{~g}$, e volume do hidrolato coletado de $1 \mathrm{~L}$.

A partição química do hidrolato (óleo + água após o processo de arraste a vapor de água) foi realizada com diclorometano, três partições com $50 \mathrm{~mL}$ de solvente cada, separando a água do óleo ( $3 \times 50 \mathrm{~mL}$ ). A fase orgânica foi secada com sulfato de sódio anidro, filtrado, e o solvente removido sob pressão reduzida em evaporador rotativo. Determinou-se a massa (g) de óleo obtido calculando-se o rendimento de óleo em relação à matéria seca da planta. 


\section{RESULTADO E DISCUSSÃO}

Avaliando os processos de secagem, secador a gás ou estufa, e considerando todas as embalagens ao longo do tempo, observou-se que apesar de existir pequena diferença nos teores de óleo, não existiu diferença significativa $(p>0,05)$ de acordo com a análise de variância entre os dois processos de secagem utilizados sobre as embalagens (Tabela 1).

TABELA 1. Valores médios dos teores de óleo de carqueja no secador a gás e em estufa em diferentes embalagens.

\begin{tabular}{ccc}
\hline Secadores & Média & Desvio Padrão \\
\hline EST & 0,026205 & 0,006067 \\
SG & 0,027314 & 0,005702 \\
\hline
\end{tabular}

Analisando o tipo de secador em relação às embalagens de armazenamento nota-se que não houve diferenças entre os processos de secagem e as embalagens; no entanto, observou se que a embalagem de polietileno promoveu decréscimo acentuado no teor de óleo essencial.

Portanto, das três embalagens avaliadas, as que mantiveram mais uniformemente o teor de óleo de carqueja foram as embalagens de vidro e kraft.

Mesmo visualmente as plantas que foram armazenadas em kraft, mantiveram ao longo do ano a coloração e a intensidade do aroma. O mesmo aconteceu com o vidro, porém, neste caso, houve leve descoloração nas folhas. O polietileno foi, notoriamente, a embalagem que menos preservou a integridade física do produto. O polietileno é uma das embalagens mais sugeridas em armazenamento por períodos curtos de tempo, pois não protege adequadamente a droga vegetal ao longo do tempo.

As diferenças no teor de óleo nas embalagens testadas, quando se utilizou a secagem em estufa, são significativas estatisticamente $(p<0,05 \%)$. Portanto, os teores de óleo no produto armazenado nas embalagens de vidro e kraft podem ser entendidos como sendo iguais e, mesmo com as médias dos teores de óleo essencial no armazenamento em vidro sendo maiores, as duas embalagens não promoveram diferenças entre si, o que indica que para o parâmetro "óleo essencial" ambas podem ser utilizadas no armazenamento da carqueja ao longo de um ano, sem que ocorra grande variação nos teores de óleo neste período.

O que dita a escolha da embalagem é o destino que a droga vegetal terá. Se o período de armazenamento for curto, as três embalagens mantêm o teor de óleo, no entanto, se for por período maior, como neste caso, um ano, as melhores opções são o vidro e o kraft, sendo que o papel kraft mantém as características avaliadas de forma mais uniforme ao longo do tempo.

O plástico é um dos materiais mais utilizados em embalagens, pois possui resistência, transparência e tem permeabilidade relativamente baixa ao vapor de água. É quimicamente inerte e praticamente não possui odor e nem transmite sabor significativo aos alimentos (Cabral et al., 1978; Midio e Martins, 2002). É o filme plástico a embalagem mais utilizada no Brasil e caracteriza-se pela resistência, baixo custo, disponibilidade, entre outros, além de ser barreira ao vapor de água e não

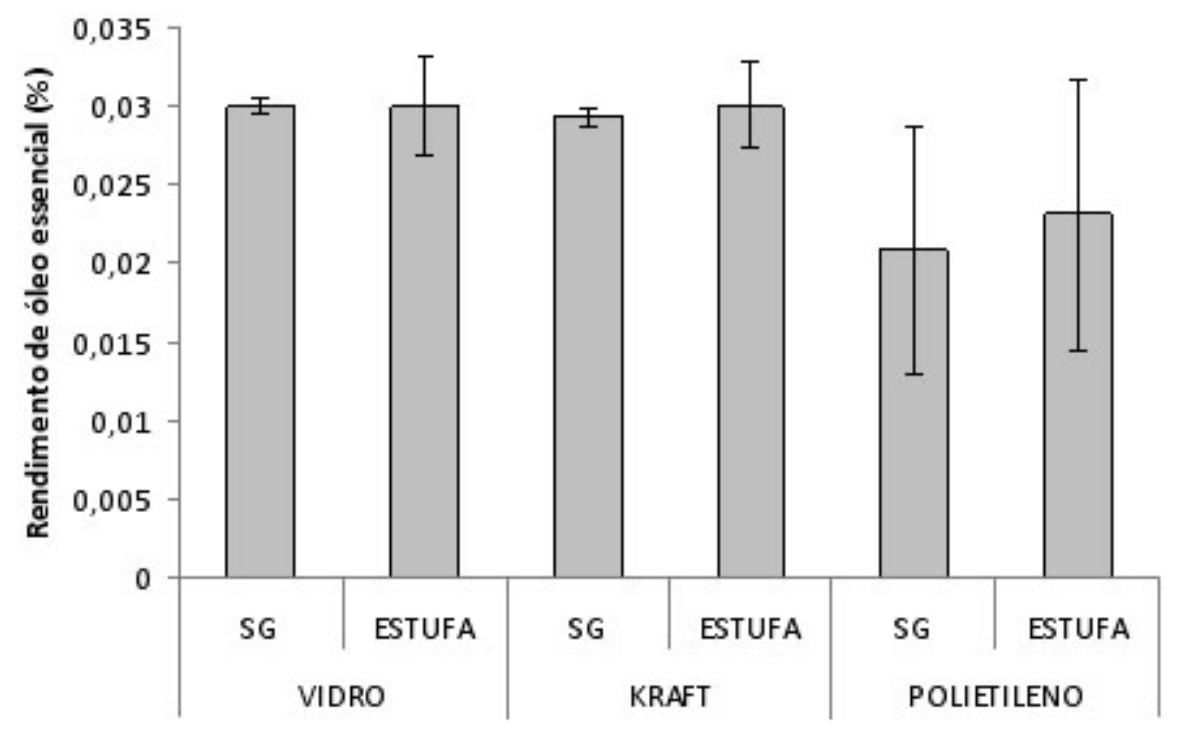

FIGURA 1. Avaliação do rendimento de óleo essencial (\%) em diferentes processos de secagem (secador a gás/ SG e Estufa com circulação forçada de ar) e embalagens (vidro, Kraft e polietileno) armazenadas pelo período de um ano. 
ser ao oxigênio (Gava, 1994).

No entanto, no caso de plantas medicinais aromáticas, acondicionadas por longos períodos, pode ocorrer perda gradual do aroma, uma vez que é permeável a muitos óleos essenciais, além do que, a transparência pode acelerar o processo de degradação das substâncias ativas, gerando um produto de baixa qualidade. Esta embalagem quando utilizada deve ser acondicionada ao abrigo da luz e para produto que tenha consumo rápido, não ficando armazenado por muito tempo.

As embalagens de vidro e Kraft mantiveram o teor de óleo por maior período de tempo. Apesar do teor de óleo essencial nesta espécie ser baixo, independente do tipo de secador utilizado, houve a preservação desta pequena quantidade em função da_embalagem adequada.

Silva et al. (1999), avaliando a qualidade de três plantas medicinais, orégano, mil folhas e salsa, secas em câmara com desumidificador e armazenadas por seis meses e um ano em embalagens de vidro, saco de papel e polietileno de baixa densidade, concluíram que a qualidade microbiológica das plantas foi melhor preservada em embalagem de vidro.

Paakkonen et al. (1989), avaliando o armazenamento de algumas plantas aromáticas secas ao ar livre e armazenadas em vidro e sacos de papel, concluíram que não houve diferença significativa na avaliação sensorial do produto, sabor e aroma, ao longo de um ano de armazenamento.

Sankat e Maharaj (1996), avaliando características pós-colheita de Eryngium foetidum L., verificaram que a embalagem em pacotes de polietileno de baixa densidade retardou a degradação da clorofila e a perda de odor, mantendo o sabor. Shalaby et al. (1988), pesquisaram o efeito do armazenamento de óleo essencial de Mentha arvensis L., e observaram diferenças na composição do óleo essencial ao longo do tempo. Se todos os cuidados durante a colheita, pós colheita, e armazenamento forem realizados, o produto chegará ao final da cadeia produtiva com boas características para a comercialização.

\section{CONCLUSÃO}

A embalagem kraft, folha dupla de papel com revestimento interno de polipropileno tipo exportação, é a melhor opção para o armazenamento da carqueja.

\section{REFERÊNCIA}

BUSATTA, C. Caracterização química e atividade antimicrobiana in vitro e em alimentos dos extratos de orégano e manjerona. 2006. 93 f. Dissertação (Mestrado em Engenharia de Alimentos) - Departamento de Ciências Agrárias, Universidade Regional Integrada do Alto Uruguai das Missões, Erechim.

CARNEIRO, M.A.A.; FERNANDES, G.W. Herbivoria. Ciência Hoje, v.20, n.118, p.35-9, 1996.

CABRAL, A.C.D.; SOLER, R.M. Princípios termoplásticos utilizados na embalagem de alimentos. Boletim do ITAL, v.55, p.77-117, 1978.

CASTRO, D.M. Caracterização Isozimática, da anatomia foliar, do óleo essencial e germinação de Leonurus sibiricus L. 1998. 97p. Dissertação (Mestrado em Fitotecnia) - Universidade Federal de Viçosa, Viçosa. CASTRO, H.G. et al. Rendimento de tanino em dois acessos de carqueja (Baccharis myriocephala D.C.), em diferentes épocas de colheita em Viçosa - MG. Revista Brasileira de Plantas Medicinais, v.1, n.2, p.2933, 1999.

CASTRO, H.G.; FERREIRA, F.A. Contribuição ao estudo das plantas medicinais: CARQUEJA (Baccharis genistelloides). Viçosa: Suprema gráfica e editora Ltda, 2000. 102p.

DE MELLO, J.; PETROVICK, P.R. Quality control of Baccharis trimera (Less.) DC. (Asteraceae) hydroalcoholic extracts. Acta Farmacéutica Bonaerense, v.19, n.3, p.211-5, 2000.

DI STASI, L.C. et al. Screening in mice of some medicinal plants used for analgesic purposes in the state of São Paulo. Journal of Ethnopharmacology, v.24, n.2/3, p.205-11, 1988.

GAVA, A.J. Princípios de tecnologia de alimentos. São Paulo: Nobel, 1984. 284p.

GONZALES, A. et al. Biological screening of Uruguayan medicinal plants. Journal of Ethnopharmacology, n.39, v. 2, p.217-20, 1993.

ITO, C.I.S. et al. Atividade fungitóxica do extrato bruto de Baccharis trimera. Disponível em: <http://www.cca.uem. br/lanu6900.htm>. Acesso em: 20 mar. 2005.

JARVIS, B.B. et al. Trichothecene mycotoxins from Brazilian Baccharis species. Phytochemistry, v.30, p.789-97, 1991.

JAKIEMIU, E.A.R. Uma contribuição ao estudo do óleo essencial e do extrato de tomilho (Thymus vulgaris L.). 2008. 89p. Dissertação (Mestrado em Tecnologia de Alimentos) - Departamento de Tecnologia, Universidade Federal do Paraná, Curitiba.

KAMADA, T. Plasticidade fenotípica da morfologia e do óleo essencial em acessos de manjericão (Ocimum spp.). 1998. 59p. Dissertação (Mestrado em Fitotecnia) Universidade Federal de Viçosa, Viçosa.

KUROYANAGI, M. et al. Studies on the constituents of Baccharis genistelloides. Chemical and Pharmaceutical Bulletin, n.33, p.5075-8, 1985.

LOPES, R.C. Caracterização isozimática, divergência genética e produção de óleo essencial em acessos de Polygonum punctatum Ell. 1997. 91p. Dissertação (Mestrado em genética e melhoramento) - Universidade Federal de Viçosa, Viçosa.

LORENZI, H.; MATOS, F.J.A. Plantas medicinais no Brasil: nativas e exóticas. Nova Odessa- SP: Instituto Plantarum, 2008. 544p.

MARTINS, E.R. Morfologia interna e externa, caracterização isozimática e óleo essencial de Ocimum 
selloi Benth. 1996. 97p. Dissertação (Mestrado em Fitotecnia) -Universidade Federal de Viçosa,Viçosa. MIDIO, A.F.; MARTINS, D.I. Toxicologia de alimentos. São Paulo: Varela, 2000, 295p.

Mc GUINNESS, J.D. Migration from packaging material a need for more fundamental information. Food Additives and Contaminants, v.3, p.103-12, 1986.

PAAKKONEN, K.; MALSMTEN, T.; HYVONEN, L. Effects of drying method, parking and storage temperatura and time on the quality of dil (Anethum graveolens). Journal of Food Science, v.54, p.1485-7, 1989.

PALÁCIO, C.P.A.M. et al. Biomassa e óleo essencial de carqueja (Baccharis trimera (Less) DC.) sob influência de fontes e doses de nitrogênio. Revista Brasileira de Plantas Medicinais, v.9, n.3, p. 58-63, 2007.

PRINS, C.L.; LEMOS, C.S.L.; FREITAS, S.P. Efeito do tempo de extração sobre a composição e o rendimento do óleo essencial de alecrim (Rosmarinus officinalis). Revista Brasileira de Plantas Medicinais, v.8, n.4, p. 92-5, 2006.

SAITO, M.L.; SCRAMIN, S. Plantas aromáticas e seu uso na agricultura. Jaguariúna: Embrapa Meio Ambiente, 2000. 48p.

SANKAT, C.K., MAHARAJ, V. Shelf life of the green herb 'shado beni' (Eryngium foetidum L.) stored under refrigerated conditions. Postharvest Biology and Technology, v.7, p.109-18, 1996.

SANTOS, C.A.M.; TORRES, K.R.; LEONART, R. Plantas medicinais herbarium, flora et scientia. São Paulo: Ícone, 1988. 160p.

SCHMIDT, F.B.; MARQUES, L.M.; MAYWORM, M.A.S. Efeito da sazonalidade sobre o potencial antibacteriano de extratos etanólicos de Baccharis trimera (Less) DC. (Asteraceae). Revista Brasileira de Plantas Medicinais, v.10, n.2, p.1-5, 2008.

SHALABY, A.S. et al. Post harvest studies on herb and oil of Mentha arvensis L. Egyptian Journal Horticultural, v.15, n.2, p.213-24, 1988.

SILVA, F. Avaliação do teor e da composição quimica do óleo essencial de plantas medicinais submetidas a processos de secagem e armazenamento. 2005. 152p. Dissertação (Doutorado em Engenharia Agrícola) - Universidade Estadual de Campinas, Campinas.

SILVA, F. et al. Qualidade pós colheita de Achillea millefolium L., Origanum vulgare L. e Petroselium crispum (miller) A.W.Hill em três embalagens. Revista Brasileira de Plantas Medicinais, v.2, n.1, p. 37-41, 1999.

SILVA, S.R. et al. Plantas medicinais do Brasil: aspectos gerais sobre legislação e comércio. Quito: Rede Traffic America do Sul/IBAMA, 2001. 44p. (Relatório).

SIQUEIRA, N.C.S. et al. Análise comparativa dos óleos essenciais de Baccharis articulata (Lam) Pers. e Baccharis trimera (Less.) DC. (Compositae), espécies espontâneas no Rio Grande do Sul. Revista Brasileira de Farmácia, v.66, n.3, p.36-9, 1985.

SOICKE, H.; LENG-PESCHLOW, E. Characterization of flavonoids from Baccharis trimera and their antihepatotoxic properties. Planta Medica, v.53, p.379, 1987.

SOUSA, M.P. et al. Constituintes químicos de plantas medicinais brasileiras. Fortaleza: Editora UFC. 1991. 416p. ZDERO, C. et al. An unusual dimeric sesquiterpene and other constituents from Chilean Baccharis species. Phytochemystry, v.30, p.597-601, 1991. 